\title{
ANTIMICROBIAL EFFECT OF INTRACANAL SUBSTANCES
}

\author{
Cláudia de Moura CARREIRA ${ }^{1}$, Silvana Soléo Ferreira dos SANTOS ${ }^{2}$, \\ Antônio Olavo Cardoso JORGE ${ }^{3}$, José Luiz LAGE-MARQUES ${ }^{4}$
}

\author{
1- DDS, MSc, PhD student of Endodontics, Postgraduate Program in Dentistry, University of São Paulo, São Paulo, SP, Brazil. \\ 2- DDS, MSc, PhD, Assistant Professor of Microbiology and Immunology, Department of Dentistry, UNITAU, Taubaté, SP, Brazil. \\ 3- DDS, MSc, PhD, Chair Professor of Microbiology and Immunology, School of Dentistry of São José dos Campos, São Paulo State \\ University, São José dos Campos, SP, Brazil. \\ 4- DDS, MSc, PhD, Full Professor of Endodontics, University of São Paulo, São Paulo, SP, Brazil; Coordinator of the Postgraduate Program \\ in Endodontics, Department de Dentistry, UNITAU, Taubaté, SP, Brazil.
}

Corresponding address: Dra Cláudia de Moura Carreira - Praça Marechal Eduardo Gomes, 50 - HTO, apt. 307 - 12228-900 - Vila das AcáciasSão José dos Campos - SP - Phone: 551239474157 - Cel 551281470422 - e-mail: cmcarreira@yahoo.com.br

Received: November 7, 2005 - Modification: September 15, 2006 - Accepted: August 27, 2007

\begin{abstract}
$T_{n}$ n some situations, endodontic infections do not respond to therapeutic protocol. In these cases, it is suggested the administration of an alternative intracanal medication that presents a wide spectrum of action and has an in-depth effect on the root canal system. The purpose of this study was to assess the antimicrobial action of ciprofloxacin, metronidazole and polyethylene glycol and natrosol vehicles with different associations and concentrations. The minimum inhibitory concentration (MIC) was determined by using the agar dilution method. The culture media (Müller-Hinton agar) were prepared containing antimicrobial agents at multiple two-fold dilutions of 0.25 to $16 \mu \mathrm{g} / \mathrm{mL}$, and with the vehicles at the concentrations of $50,45,40$, 35,30 and $25 \%$. Twenty-three microbial strains were selected for the study. Metronidazole was not capable of eliminating any of the tested microorganisms. The association of ciprofloxacin with metronidazole resulted in a reduction of the MIC. The vehicle polyethylene glycol inhibited the growth of $100 \%$ of the tested strains, while natrosol inhibited $18 \%$ of the strains. Ciprofloxacin formulations with polyethylene glycol presented better effects than those of formulations to which metronidazole was added. It was possible to conclude that ciprofloxacin presented antimicrobial action against all tested bacterial strains, and its association with metronidazole was synergic. The vehicle polyethylene glycol showed antimicrobial effect and the ciprofloxacin/polyethylene glycol association was the most effective combination for reducing the tested bacteria and yeasts.
\end{abstract}

Uniterms: Ciprofloxacin; Metronidazole; Polyethylene glycols; Natrosol; Endodontics.

\section{INTRODUCTION}

Microbial control in the endodontic system represents a challenge to the solution of refractory infections when chemical and surgical procedures do not provide the desired response for control of infection.

The chemomechanical preparation used during endodontic therapy is the main factor responsible for eliminating the microorganisms lodged into the root canal system $^{20}$. In most clinical situations, this procedure is sufficient to obtain success and guarantee periapical tissue repair.

However, some cases demand the application of intracanal medication as an adjuvant therapy to resolve the infection. This occurs because microorganisms may colonize the endodontic system, demanding deeper and more guaranteed therapeutic action. In these cases, intracanal medication not only plays the role of inflammatory reaction moderator, but is also imperative to combat the remaining infection.

In most cases, facultative anaerobic microorganisms are more resistant to endodontic procedures than the anaerobic ones ${ }^{10,16,23}$. This resistance is related to microbial capacity to remain in a latent phase, at a low metabolic rate for a long period of time. However, environmental changes, such as coronal leakage, may lead to activation of these microorganisms and their consequent proliferation ${ }^{6,14}$.

Associations of antimicrobial agents have been proposed with the goal of increasing the spectrum of action and combating the persistent infection ${ }^{9,11,17}$. The choice of vehicle associated with intracanal medication is also of paramount importance, as they are responsible for transporting the drug to the interior of the root canal systems and for the speed of its diffusion ${ }^{24}$.

The purpose of this study was to investigate the antimicrobial action of ciprofloxacin hydrochloride and 
metronidazole, and the vehicles polyethylene glycol and natrosol, either alone or associated, supported by the fact that intracanal medication is an important adjuvant of the endodontic treatment protocol.

\section{MATERIALAND METHOD}

Twenty-three microbial strains were selected from the American Type Culture Collection (ATCC) and the University of Taubaté Culture Collection (CCUT) (Table 1).

The susceptibility of the microorganisms to the antimicrobial agents metronidazole (Henrifarma, China) and ciprofloxacin hydrochloride (Pharmanostra, USA) and to the vehicles polyethylene glycol (PM 1000) and natrosol, was assessed, either alone and in the following associations: a) ciprofloxacin and metronidazole; b) ciprofloxacin and natrosol; c) ciprofloxacin and polyethylene glycol; d) metronidazole and natrosol; e) metronidazole and polyethylene glycol; f) ciprofloxacin, metronidazole and natrosol; and, g) ciprofloxacin, metronidazole and polyethylene glycol. The antimicrobial agents were submitted to filtration $(0.22 \mu \mathrm{m}$, Millipore membrane $)$ and the vehicles were sterilized by gamma radiation $\left({ }^{60} \mathrm{CO}\right.$, GAMMACELL, Atomic Energy of Canada Limited, Canada).

The Müller-Hinton agar (Difco, Detroit, MI, USA) dilution method was used to determine the minimum inhibitory concentration $(\mathrm{MIC})^{15}$. Culture media were prepared, adding antimicrobial agents in two-fold serial dilutions, obtaining final concentrations of 16 to $0.25 \mu \mathrm{g} / \mathrm{mL}$ of medium. For the vehicles, culture media containing 50, 45, 40, 35, 30 and $25 \%$ were used. For the associations, the substances were added to the culture media at the same concentrations and percentages used for the substances tested separately, in a total of 292 combinations. For each test, Petri plates containing only Müller-Hinton agar were used as control. The selected microorganisms were plated in Müller Hinton agar and incubated at $37^{\circ} \mathrm{C}$ for 24 hours. After growth and morphologic confirmation in smears stained by Gram method, suspensions were prepared with isolated colonies and sterile saline in accordance with tube 0.5 (approximately $1.5 \times 10^{8}$ cells $/ \mathrm{ml}$ ) of McFarland scale, for the bacteria, and tube 2 (approximately $10^{6}$ cells $/ \mathrm{ml}$ ) for yeasts (recommendation of the National Committee for Clinical Laboratory Standards $\left.{ }^{12,13}\right)$. Next, aliquots of the suspensions were placed into the wells of the Steers replicator, and then plated in the culture media. The plates were incubated at $37^{\circ} \mathrm{C}$ for 24 hours and the occurrence of microbial growth was evaluated. The MIC was defined at the lowest concentration of the drug that inhibited microbial growth. The experimental data were collected for descriptive statistics of the MIC of each strain.

\section{RESULTS}

Minimum inhibitory concentration results for the antimicrobial agents ciprofloxacin and metronidazole, and for the vehicles (natrosol and polyethylene glycol) are shown in Table 2. The bacteria were susceptible to ciprofloxacin while the fungi were resistant to it. All tested microorganisms were resistant to metronidazole. Considering the vehicles, polyethylene glycol showed the most effective microbial inhibition.

Table 3 shows the results of the association of ciprofloxacin with the vehicles. Ciprofloxacin/polyethylene glycol association increased the antimicrobial effects of both products. Ciprofloxacin/natrosol association partially increased the effects of the products, also presenting effects against Candida species.

Table 4 shows the results of the association of metronidazole with the tested vehicles. Metronidazole/ polyethylene glycol association inhibited all microbial strains, using low concentrations of the antimicrobial agent, as well as low percentages of polyethylene glycol. Most strains remained resistant to the action of the association of metronidazole with natrosol.

The MIC values of ciprofloxacin/metronidazole association and these with the vehicles are expressed in

TABLE 1- Microorganisms selected for the experiment and the source of the strains

Microorganism

Strains

(number of strains)

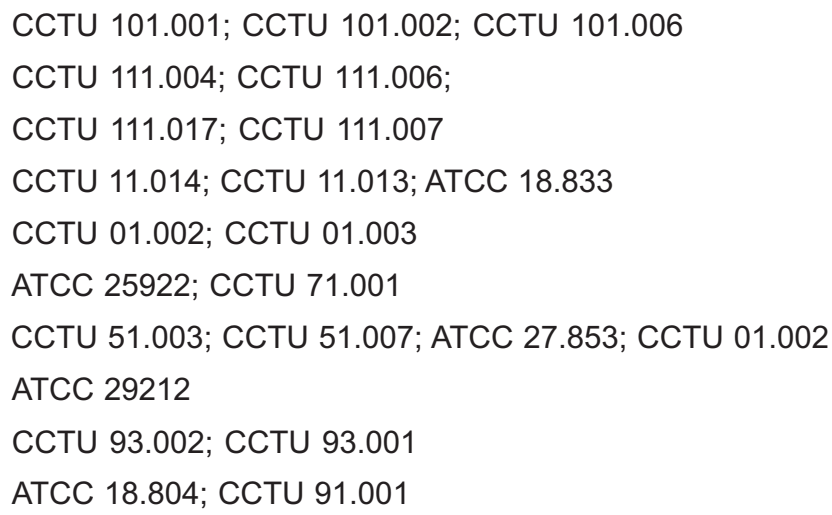

CCTU 101.001; CCTU 101.002; CCTU 101.006

CCTU 111.004; CCTU 111.006;

CCTU 111.017; CCTU 111.007

CCTU 11.014; CCTU 11.013; ATCC 18.833

CCTU 01.002; CCTU 01.003

ATCC 25922; CCTU 71.001

CCTU 51.003; CCTU 51.007; ATCC 27.853; CCTU 01.002

ATCC 29212

CCTU 93.002; CCTU 93.001

ATCC 18.804; CCTU 91.001 
Table 5. The association of ciprofloxacin with metronidazole presented lower MIC for the bacteria than ciprofloxacin alone, except for Escherichia coli. Polyethylene glycol added to the formulation eliminated all bacteria, at the lowest concentration of antimicrobial agents and vehicles. The performance of ciprofloxacin/metronidazole/polyethylene glycol association was equivalent or lowest to the association ciprofloxacin/polyethylene glycol.

In all plates of culture media in which the antimicrobial agents and vehicles were not added (controls), there was growth of all microbial strains.

\section{DISCUSSION}

Some clinical cases do not respond to the traditional protocol used in endodontic therapy. These difficulties are generally related to the anatomic characteristics of the root canal system ${ }^{7}$, resistance to antimicrobial agents ${ }^{3,6}$ and the presence of apical biofilm ${ }^{18,25}$. For cases of resistance to antimicrobial agents, the use of alternative medications, or the combination of antimicrobial agents is suggested to increase the spectrum of action and act particularly on the facultative anaerobic microorganisms.

In Endodontics, antimicrobial agents are used topically, due to the absence of blood irrigation in the root canal

TABLE 2- Minimum inhibitory concentrations (MIC) of ciprofloxacin hydrochloride, metronidazole, polyethylene glycol and natrosol for the tested microorganisms

\begin{tabular}{|c|c|c|c|c|c|}
\hline \multirow[t]{2}{*}{ Species } & \multirow[t]{2}{*}{ No. of Strains } & \multirow{2}{*}{$\begin{array}{c}\text { MIC }(\mu \mathrm{g} / \mathrm{ml}) \\
\text { Ciproflocaxin }\end{array}$} & \multirow{2}{*}{$\begin{array}{l}\text { MIC }(\mu \mathrm{g} / \mathrm{ml}) \\
\text { Metronidazole }\end{array}$} & \multirow{2}{*}{$\begin{array}{c}\text { MIC (\%) } \\
\text { Polyethylene glycol }\end{array}$} & \multirow{2}{*}{$\begin{array}{l}\text { MIC (\%) } \\
\text { Natrosol }\end{array}$} \\
\hline & & & & & \\
\hline S. aureus & 3 & $0,5 \rightarrow 1$ & $\mathrm{R}$ & 30 & $35 \rightarrow R$ \\
\hline E. faecalis & 1 & 4 & $\mathrm{R}$ & $S$ & $\mathrm{R}$ \\
\hline S. mutans & 4 & 4 & $\mathrm{R}$ & $S$ & $\mathrm{R}$ \\
\hline P. aeruginosa & 4 & S & $\mathrm{R}$ & $\mathrm{S} \rightarrow 30$ & $40 \rightarrow \mathrm{R}$ \\
\hline E. coli & 2 & $S \rightarrow 1$ & $\mathrm{R}$ & $\mathrm{s}$ & $40 \rightarrow R$ \\
\hline E. cloacae & 2 & $S \rightarrow 1$ & $\mathrm{R}$ & $S$ & $40 \rightarrow R$ \\
\hline K. pneumoniae & 3 & $S \rightarrow 1$ & $\mathrm{R}$ & $S$ & $40 \rightarrow R$ \\
\hline C. tropicalis & 2 & $\mathrm{R}$ & $\mathrm{R}$ & 30 & $45 \rightarrow R$ \\
\hline C. albicans & 2 & $\mathrm{R}$ & $\mathrm{R}$ & $30 \rightarrow 40$ & $45 \rightarrow R$ \\
\hline
\end{tabular}

$\mathrm{R}=$ resistant at the highest concentration tested $(16 \mu \mathrm{g} / \mathrm{ml}$ or $50 \%) ; \mathrm{S}=$ sensitive at the lowest concentration tested $(0.25 \mu \mathrm{g} /$ $\mathrm{ml}$ or $25 \%) ; \rightarrow$ interval of concentration of the tested products

TABLE 3- Variation in MIC of the association of ciprofloxacin with metronidazole $(0.25$ to $16 \mu \mathrm{g} / \mathrm{ml})$ and with polyethylene glycol (25 to $50 \%)$ and ciprofloxacin $(0.25$ to $16 \mu \mathrm{g} / \mathrm{ml})$ with natrosol (25 to $50 \%)$ for the tested microorganisms

\begin{tabular}{|c|c|c|c|c|c|}
\hline \multirow[t]{3}{*}{ Species } & \multirow[t]{3}{*}{ No. of Strains } & \multicolumn{2}{|c|}{ CIM } & \multicolumn{2}{|c|}{ CIM } \\
\hline & & \multicolumn{2}{|c|}{ Ciprofloxacin + polyethylene glycol } & \multicolumn{2}{|c|}{ Ciprofloxacin + natrosol } \\
\hline & & $\mathrm{mg} / \mathrm{ml}$ & $\%$ & $\mathrm{mg} / \mathrm{ml}$ & $\%$ \\
\hline S. aureus & 3 & $S$ & $S$ & $\mathrm{~S} \rightarrow 4$ & $25 \rightarrow 50$ \\
\hline E. faecalis & 1 & S & S & 4 & 25 and 50 \\
\hline S. mutans & 4 & $S$ & $S$ & 4 & 50 \\
\hline$P$. aeruginosa & 4 & S & S & $0.5 \rightarrow 1$ & 50 \\
\hline E. coli & 2 & S & $\mathrm{S}$ & 0.25 & 25 and 45 \\
\hline E. cloacae & 2 & S & S & 0.5 & 25 and 45 \\
\hline K. pneumoniae & 3 & S & S & 0.25 & 25 and 50 \\
\hline C. tropicalis & 2 & $S$ & 35 & $2 \rightarrow 4$ & 50 \\
\hline C. albicans & 2 & $S$ & 35 & 4 & 50 \\
\hline
\end{tabular}

$\mathrm{S}=$ sensitive at the lowest concentration tested $(0.25 \mu \mathrm{g} / \mathrm{ml}$ or $25 \%) ; \rightarrow$ interval of concentration of the tested products 
system at the time of therapy. In most cases, intracanal medication is used in aqueous solution, allowing the system to be well filled. However, the capacity to remain there and to have a prolonged action is limited and it is in contact with the healthy or contaminated periodontal fluid. These fluids rapidly dilute the medication and the canal becomes clinically empty between sessions.

The vehicle associated with the antimicrobial agents has a strict relationship with the time of action of the antimicrobial agent $^{19}$, penetration of the medication in the root canal system $^{2,24}$, in addition to the dissociation of the principle of the drugs ${ }^{5,8}$.

The results of the present study demonstrated, although metronidazole had no action against the tested microorganisms, which was expected, the ciprofloxacin/ metronidazole association resulted in a positive interaction, that is, there was synergism in this proposed combination. Slots, et al. ${ }^{21}$ (1990) found that the ciprofloxacin/ metronidazole association was more effective against enterobacteria collected from periodontal pockets than ciprofloxacin used alone.

Greater synergism was observed in the ciprofloxacin/ polyethylene glycol association. All MIC values for this association were lower than those of ciprofloxacin used alone or combined with metronidazole. Another advantage of the association ciprofloxacin/polyethylene glycol was

TABLE 4- Variation in MIC of the association of metronidazole $(0.25$ to $16 \mu \mathrm{g} / \mathrm{ml})$ with polyethylene glycol (25 to $50 \%)$ and metronidazole $(0.25$ to $16 \mu \mathrm{g} / \mathrm{ml})$ with natrosol $(25$ to $50 \%)$ for the tested microorganisms

\begin{tabular}{|c|c|c|c|c|c|}
\hline \multirow[t]{2}{*}{ Species } & \multirow[t]{2}{*}{ No. of Strains } & \multicolumn{2}{|c|}{ CIM } & \multicolumn{2}{|c|}{$\begin{array}{c}\text { CIM } \\
\text { Metronidazole + natrosol }\end{array}$} \\
\hline & & $\mathrm{mg} / \mathrm{ml}$ & $\%$ & $\mathrm{mg} / \mathrm{ml}$ & $\%$ \\
\hline S. aureus & 3 & 1 & $\mathrm{~s}$ & $8 \rightarrow 16$ & $35 \rightarrow 50$ \\
\hline E. faecalis & 1 & 2 & S & $\mathrm{R}$ & $\mathrm{R}$ \\
\hline S. mutans & 4 & $S$ & $S$ & $R$ & $\mathrm{R}$ \\
\hline P. aeruginosa & 4 & $S$ & $S$ & $\mathrm{R}$ & $\mathrm{R}$ \\
\hline E. coli & 2 & $s$ & $\mathrm{~s}$ & 4 & $50 \rightarrow R$ \\
\hline E. cloacae & 2 & $S \rightarrow 0,5$ & $\mathrm{~s}$ & 2 and 4 & 35 \\
\hline K. pneumoniae & 3 & 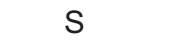 & $\mathrm{s}$ & $1 \rightarrow R$ & $45 \rightarrow R$ \\
\hline C. tropicalis & 2 & $S \rightarrow 16$ & 30 & $\mathrm{R}$ & $\mathrm{R}$ \\
\hline C. albicans & 2 & $0.5 \rightarrow 8$ & 30 & $\mathrm{R}$ & $\mathrm{R}$ \\
\hline
\end{tabular}

$\mathrm{R}$ - resistant at the highest concentration tested $(16 \mu \mathrm{g} / \mathrm{ml}$ or $50 \%)$

$\mathrm{S}-$ sensitive at the lowest concentration tested $(0.25 \mu \mathrm{g} / \mathrm{ml}$ or $25 \%)$

$\rightarrow$ interval of concentration of the tested products

TABLE 5- Variation in MIC of the association of ciprofloxacin with metronidazole $(0.25$ to $16 \mathrm{mg} / \mathrm{ml})$ and with polyethylene glycol (25 to $50 \%$ ) or natrozol (25 to $50 \%$ ) for the tested microorganisms

\begin{tabular}{|c|c|c|c|c|c|c|}
\hline \multirow[t]{2}{*}{ Species } & \multirow[t]{2}{*}{ No. of Strains } & \multirow[t]{2}{*}{$\begin{array}{l}\text { CIM } \\
\text { Ciprofloxacin + } \\
\text { Metronidazole } \\
\text { mg/ml }\end{array}$} & \multicolumn{2}{|c|}{\begin{tabular}{l}
\multicolumn{1}{c}{ CIM } \\
Ciprofloxacin + \\
Metronidazole + \\
Polyethylene glycol
\end{tabular}} & \multicolumn{2}{|c|}{$\begin{array}{l}\quad \text { CIM } \\
\text { Ciprofloxacin + } \\
\text { Metronidazole + } \\
\text { Natrosol }\end{array}$} \\
\hline & & & $\mathrm{mg} / \mathrm{mL}$ & $\%$ & $\mathrm{mg} / \mathrm{ml}$ & $\%$ \\
\hline S. aureus & 3 & 0.25 & $\mathrm{~S}$ & $\mathrm{~S}$ & 0.5 & $S \rightarrow 45$ \\
\hline E. faecalis & 1 & 2 & $S$ & $S$ & 4 & $S \rightarrow 50$ \\
\hline S. mutans & 4 & 2 & $\mathrm{~S}$ & $\mathrm{~S}$ & 4 & $S \rightarrow 50$ \\
\hline$P$. aeruginosa & 4 & 0.25 e 1 & $S$ & $S$ & $0.5 \rightarrow 1$ & $S \rightarrow 50$ \\
\hline E. coli & 2 & 0.25 & $S$ & $\mathrm{~S}$ & $0.5 \rightarrow 1$ & $40 \rightarrow 50$ \\
\hline E. cloacae & 2 & 0.25 & $\mathrm{~S}$ & $\mathrm{~S}$ & $0.5 \rightarrow 4$ & $\mathrm{~S}$ \\
\hline K. pneumoniae & 3 & 0.25 & S & $\mathrm{S}$ & $S \rightarrow 4$ & $S \rightarrow 50$ \\
\hline C. tropicalis & 2 & $\mathrm{R}$ & $1 \rightarrow 2$ & 35 & 4 & $S \rightarrow 50$ \\
\hline C. albicans & 2 & $\mathrm{R}$ & $\mathrm{S} \rightarrow 4$ & $S \rightarrow 35$ & 4 & $S \rightarrow 50$ \\
\hline
\end{tabular}

$\mathrm{R}=$ resistant at the highest concentration tested $(16 \mu \mathrm{g} / \mathrm{ml}$ or $50 \%) ; \mathrm{S}=$ sensitive at the lowest concentration tested $(0.25 \mu \mathrm{g} /$ $\mathrm{ml}$ or $25 \%) ; \rightarrow$ interval of concentration of the tested products. 
the effective action on yeasts resistant to the other formulations.

All tested bacteria were sensitive to the association of ciprofloxacin and metronidazole with the vehicle polyethylene glycol, while $C$. albicans and $C$. tropicalis were eliminated with this vehicle in concentrations equal to or lower than $35 \%$ by volume of the solution.

Metronidazole at $16 \mu \mathrm{g} / \mathrm{mL}$ concentration and lower, associated with polyethylene glycol at a percentage of 30 to $50 \%$, was responsible for eliminating all strains, including the yeasts. As the volume of polyethylene glycol in the culture media was reduced, the number of resistant strains increased.

The relative frequency of microbial death in the metronidazole and natrosol combination was $24 \%$. The results obtained were expected, since the action spectrum of metronidazole is selective for anaerobic bacteria Therefore, the importance of the results is based on the knowledge of the interaction of metronidazole with the other studied substances.

The effectiveness of the association of ciprofloxacin, metronidazole and natrosol shows a trend towards $100 \%$ sensitivity, as the concentration of the antimicrobial agents increases. For this combination of substances, the highest MIC was $4 \mu \mathrm{g} / \mathrm{mL}$ and $50 \%$ of natrosol. Similarity of the results with the group without the addition of metronidazole was noted. As metronidazole did not present action against the facultative anaerobic bacteria tested in this experiment, further studies are necessary with other species of microorganisms to assess the feasibility of its application.

The vehicle polyethylene glycol was capable of eliminating $100 \%$ of the microorganisms tested with MIC $40 \%$. As the volume of polyethylene glycol was diminished (below 30\%), some microorganisms were capable of growing, particularly C. albicans and C. tropicalis. Polyethylene glycol was shown to be more effected when compared with natrosol. It is interesting to point out that polyethylene glycol (PM 1000) is the vehicle that allowed greater dentinal penetration of the association calcium hydroxide, ciprofloxacin and metronidazole ${ }^{24}$. This association is frequently proposed in the medical area for intra-abdominal infections ${ }^{1,4,22}$.

When studied separately, natrosol prevented the growth of some microorganisms, particularly when administered in higher percentages. However, at no time was it capable of inhibiting the growth of all the microorganisms.

The susceptible of the microorganisms to the vehicle polyethylene glycol was similar to that of the associations used in the present study. This suggests that the antimicrobial action demonstrated was exercised by the action of this vehicle. This may be related to the hydrophilic property of polyethylene glycol. Removing water from the culture media, the vehicle possibly did not allow microbial growth, as a certain amount of water is required to enable them to multiply and develop. It is suggested that further studies be conducted, to find whether this effect occurs inside the root canal system.

The microbial concentration used for the suspension was determined by using the standard 0.5 on the McFarland scale for bacteria and 2 for the yeasts, as the latter present a greater cellular volume ${ }^{12,13,15,18}$.

It must be emphasized that almost all clinical situations are solved by performing the simple endodontic technique, which complies with the conditional factors of good preparation of the root canal system. In spite of the usual therapeutic protocol, the medication here proposed can be indicated when the routine alternatives are not able of producing the desired effects.

\section{CONCLUSIONS}

Analysis of the results obtained by the application of the experimental model allowed the following conclusions:

- Ciprofloxacin showed antimicrobial action against all tested microbial strains, and its association with metronidazole was synergic.

- The vehicle polyethylene glycol showed antimicrobial effect.

- Ciprofloxacin associated with polyethylene glycol was the most effective combination for reducing the tested bacteria and yeasts.

\section{REFERENCES}

1- Beelen DW, Elmaagacli A, Müller KD, Hirche H, Schaefer UW. Influence of intestinal bacterial decontamination using metronidazole and ciprofloxacin or ciprofloxacin alone on the development of acute graft-versus-host disease after marrow transplantation in patients with hematologic malignancies: final results and long-term follow-up of an open-label prospective randomized trial. Blood. 1999; 93(10):3267-75

2- Camões IC, Salles MR, Chevitarese O. $\mathrm{Ca}^{2+}$ diffusion through dentin of $\mathrm{Ca}(\mathrm{OH})_{2}$ associated with seven different vehicles. J Endod. 2003; 29(12):822-5.

3- Chávez de Paz LE, Dahlén G, Molander A, Möller A, Bergenholtz G. Bactéria recovered from teeth with apical periodontitis after antimicrobial endodontic treatment. Int Endod J. 2003;36(7):500-

4- Cohn SM, Lipsett PA, Buchman TG, Cheadle WG, Milsom JW, O'Marro S, Yellin, et al. Comparison of intravenous/ oral ciprofloxacin plus metronidazole versus piperacillin/ tazobactam in the treatment of complicated intrabdominal infections. Ann. Surg. 2000;232(2):25462

5- Estrela C, Bammann LL, Sydney GB, Moura J. Efeito antimicrobiano de pastas de hidróxido de cálcio sobre bactérias aeróbias facultativas. Rev Facul Odont Bauru. 1995;3(1/4):109-14.

6- Hancock HH, Sigurdsson A, Trope M, Moiseiwitsch J. Bacteria isolated after unsuccessful endodontic treatment in a North American population. Oral Surg Oral Med Oral Pathol. 2001;91(5):579-86.

7- Ida RD, Gutmann JL. Importance of anatomic variables in endodontic treatment outcomes: case report. Endod Dent Traummatol. 1995;11(4):199-203.

8- Lage-Marques JL, Conti R, Antoniazzi JH, Gutz I. Avaliação da velocidade de dissociação iônica do hidróxido de cálcio associado a diferentes veículos. Rev Odontol Univ São Paulo. 1994;8(2):81-7. 
9- Lage-Marques JL, Antoniazzi JH. Quando a medicação intracanal é fundamental para o sucesso da terapia endodôntica. In: Feller C, Gorab R. Atualização na clínica odontológica. São Paulo: Artes Médicas; 2000. v.1, p.67-99.

10 - Molander A, Reit C, Dahlén G, Kvist T. Microbiological status of root-filled teeth with apical periodontitis. Int Endod J. 1998;31(1):17.

11 - Molander A, Dahlén G. Evaluation of the antibacterial potencial of tetracycline or erythromycin mixed with calcium hydroxide as intracanal dressing against Enterococcus faecalis in vitro. Oral Surg Oral Med Oral Pathol Oral Radiol Endod. 2003;96(6):744-50.

12 - National Committee for Clinical Laboratory Standards. Methods for dilution antimicrobial susceptobility tests for bacteria that grow aerobically. 5.ed. Approved Standart: 7-A5 Wayne, Pennsylvania, EUA, NCCLS; 2000.

13 - National Committee for Clinical Laboratory Standards. Reference method for broth dilution antifungal susceptibility testing of yeasts. 5. ed. Approved standard M27-A2, Wayne Pennsylvania, EUA, NCCLS; 2002

14 - Noda M, Komatsu H, Satoshi I, Sano H. Antibiotic susceptibility of bacteria detected from the root canal exudate of persistent apical periodontitis. J Endod. 2000;26(4):221-4.

15- Oplustil CP. Procedimentos básicos em microbiologia clínica. 1.ed. São Paulo: Savier; 2000. 254p.

16- Pinheiro ET, Gomes BPFA, Ferraz CCR, Teixeira FB, Zaia AA, Souza-Filho FJ. Evaluation of root canal microorganisms isolated from teeth with endodontic failure Oral Microbiol Immunol. 2003;18(2):100-3.

17- Sato T, Hoshino E, Uematsu H, Noda T. In vitro antimicrobial susceptibility to and their antimicrobial susceptibility. Oral Microbiol Immunol. 2003;18(2):100-3

18 - Sen BH, Piskin B, Demirci T. Observation of bacteria and fungi in infected root canals and dentinal tubules by SEM. Endod Dent Traumatol. 1995;11(1):6-9.

19- Siqueira JF, Uzeda M. Influence of different vehicles on the antibacterial effect of calcium hydroxide. J Endod. 1998;24(10):6635 .

20 - Sjögren U, Sundqvist G, Sweden U. Bacteriologic evaluation of ultrasonic root canal instrumentation. Oral Surg Oral Med Oral Pathol. 1987;63(3):66-70.

21 - Slots J, Feik D, Rams TE. In vitro antimicrobial sensitivity of enteric rods and pseudomonades from advanced adult periodontitis. Oral Microbiol Immunol. 1990;5(5):298-301.

22- Solomkin JS, Reinhart HH, Dellinger EP, Bohnen JM, Rotstein $\mathrm{OD}$, Vogel SB, et al. Results of randomized trial comparing sequential intravenous/ oral treatment with ciprofloxacin plus metronidazole to imipenem/cilastatin for intra-abdominal infections. Ann. Surg. 1996;223(3):303-15

23 - Sundqvist G, Fidgor D, Persson S, Sjörgren U. Microbiologic analysis of teeth with failed endodontic treatment and the outcome of conservative re-treatment. Oral Surg Oral Med Oral Pathol. 1998;85(1):86-93.

24- Takeuti ML, Lage-Marques JL, Antoniazzi JH. Penetração dentinária da associação de hidróxido de cálcio, ciprofloxacina e metronidazol variando o veículo. Rev Pós-Grad. 1997;4(2):146-52.
25- Tronstad L, Barnett F, Cervone F. Periapical bacterial plaque in teeth refractory to endodontic treatment. Endod Dent Traumatol. 1990;6(2):73-7. 